\title{
FAILURE MODES IN HIGH-POWER LITHIUM-ION BATTERIES FOR USE IN HYBRID ELECTRIC VEHICLES
}

\author{
R. Kostecki, X. Zhang*, P. N. Ross*, Jr., F. Kong, \\ S. Sloop, J. B. Kerr, K. Striebel, E. Cairns, F. McLarnon \\ Environmental Energy Technologies Division, and \\ *Materials Sciences Division \\ Lawrence Berkeley National Laboratory \\ Berkeley, California 94720
}

The Advanced Technology Development (ATD) Program seeks to aid the development of high-power lithium-ion batteries for hybrid electric vehicles. Nine 18650-size ATD baseline cells were tested under a variety of conditions. The cells consisted of a carbon anode, $\mathrm{LiNi}_{0.8} \mathrm{Co}_{0.2} \mathrm{O}_{2}$ cathode and $\mathrm{DEC}-\mathrm{EC}-\mathrm{LiPF}_{6}$ electrolyte, and they were engineered for high-power applications. Selected instrumental techniques such as synchrotron IR microscopy, Raman spectroscopy, scanning electron microscopy, atomic force microscopy, gas chromatography, etc. were used to characterize the anode, cathode, current collectors and electrolyte from these cells. The goal was to identify detrimental processes which lead to battery failure under a high-current cycling regime as well as during storage at elevated temperatures. The diagnostic results suggest that the following factors contribute to the cell power loss: a) SEI deterioration and non-uniformity on the anode, b) morphology changes, increase of impedance and phase separation on the cathode, c) pitting corrosion on the cathode $\mathrm{Al}$ current collector, and d) decomposition of the $\mathrm{LiPF}_{6}$ salt in the electrolyte at elevated temperature.

\section{INTRODUCTION}

The Advanced Technology Development (ATD) Program is a new effort by the U.S. Department of Energy to aid the development of lithium-ion batteries for hybrid electric vehicle (HEV) applications. The ATD Program is a joint effort of five DOE National Laboratories: Argonne National Laboratory (ANL), Sandia National Laboratories (SNL), Idaho National Engineering and Environmental Laboratory (INEEL), Brookhaven National Laboratory (BNL), and the Lawrence Berkeley National Laboratory (LBNL).

A baseline cell chemistry was identified as a carbon anode (negative electrode), a $\mathrm{LiNi}_{0.8} \mathrm{Co}_{0.2} \mathrm{O}_{2}$ cathode (positive electrode) and DEC-EC-LiPF 6 electrolyte. Nine ATD baseline cells were fabricated by PolyStor, Inc. according to a design provided by ANL and tested at INEEL, ANL and SNL. These cells were not optimized, and were used only in studies of cell components under high-power battery simulations.

High-current pulse profiles were generated specifically for performance characterization of these batteries in the HEVs applications in contrast to the constantcurrent profiles typically used in the characterization of lithium-ion batteries in portable devices. Nine 18650-size ATD cells were tested under a variety of conditions. All cells 
had undergone two formation cycles and one discharge, and some were placed on calendar-life tests (the cells were stored at a certain temperature) or cycle-life tests (the cell was subjected to a charge-neutral profile with 3,6, or $9 \%$ variation of the state of charge) [1]. The power performance (W/kg) of all cells decayed by $15-30 \%$ during cyclelife and calendar-life testing. The cells were then discharged at the $\mathrm{C} / 25$ rate and stored at $10^{\circ} \mathrm{C}$. Cells were opened in a helium-atmosphere dry box, followed immediately by diagnostics.

Selected diagnostic techniques such as synchrotron IR microscopy, Raman spectroscopy, scanning electron microscopy, atomic force microscopy, gas chromatography, electrochemical impedance spectroscopy and etc. were used to characterize the anode, cathode, current collectors, and electrolyte from these cells.

\section{EXPERIMENTAL}

The cell characteristics are listed in Table 1 and a summary of the test conditions for all nine cells is given in Table 2. Detailed description of testing parameters and diagnostic experimental procedures can be found in [2].

Table 1 Generation 1 Cell Components

\begin{tabular}{|l|l|l|}
\hline Component & Anode & Cathode \\
\hline active material & $75 \%$ MCMB graphite & $\begin{array}{l}84 \% \mathrm{LiNi}_{0.8} \mathrm{Co}_{0.2} \mathrm{O}_{2} \\
\text { Sumitomo }\end{array}$ \\
\hline binder & $\begin{array}{l}\text { 8\% polyvinylidene fluoride } \\
\text { Kurecha C }\end{array}$ & $\begin{array}{l}8 \% \text { polyvinylidene fluoride } \\
\text { Kurecha 1100 (homopolymer) }\end{array}$ \\
\hline additive & NA & $\begin{array}{l}4 \% \text { acetylene black, Shawinigan } \\
4 \% \text { graphite, SFG-6 }\end{array}$ \\
\hline current collector & $11 \mu \mathrm{m} \mathrm{Cu}$ foil & $28 \mu \mathrm{m} \mathrm{Al} \mathrm{foil-uncoated}$ \\
\hline loading & $5.5 \mathrm{mg} / \mathrm{cm}^{2}$ & $10.2 \mathrm{mg} / \mathrm{cm}^{2}$ \\
\hline separator & $37 \mu \mathrm{m}$ three-layer $(\mathrm{PE} / \mathrm{PP} / \mathrm{PE})$ from Celgard \\
\hline electrolyte & $1 \mathrm{M} \mathrm{LiPF}$ in EC/DEC (1:1), LP-40 from EM Science (Merck) \\
\hline
\end{tabular}

Table 2 Test conditions of the ATD GEN-1 cells

\begin{tabular}{|c|c|c|c|c|}
\hline Cell number & SOC & $\Delta$ SOC & Temp $\left({ }^{\circ} \mathrm{C}\right)$ & $\begin{array}{c}\text { Testing period } \\
\text { (weeks })\end{array}$ \\
\hline 1 & 0 & 0 & 20 & 0 \\
\hline 2 & 80 & 0 & 40 & 4 \\
\hline 3 & 60 & 0 & 50 & 12 \\
\hline 4 & 80 & 0 & 60 & 4 \\
\hline 5 & 60 & 0 & 70 & 2 \\
\hline 6 & 60 & 3 & 40 & 2 \\
\hline 7 & 60 & 3 & 70 & 4 \\
\hline 8 & 60 & 9 & 40 & 2 \\
\hline 9 & 60 & 9 & 70 & \\
\hline
\end{tabular}


Ex situ IR microscopy was conducted using a Nicolet Magna 760 with Nic-Plan IR Microscope in the LBNL Advanced Light Source. A synchrotron beam of small spot size $(\sim 10 \mu \mathrm{m})$ was employed, which provides good spatial resolution and allows detailed examination of the uniformity of the SEI on electrodes. Electrode samples were harvested from various locations on the electrodes inside a dry box and then inserted into the airtight IR cells.

Model electrochemical experiments were carried out using glassy carbon as the working electrode and lithium metal as both counter and reference electrodes. The electrolyte was LP40 (Merck, Inc) dissolved in THF at a 1:1 ratio, DEC/THF (1:1) or EC dissolved in THF with a concentration of $10 \mu \mathrm{M}$, each with $0.1 \mathrm{M}$ of $\mathrm{LiClO}_{4}$. The potential was scanned from $2 \mathrm{~V}$ to $50 \mathrm{mV}\left(\mathrm{vs} \mathrm{Li} / \mathrm{Li}^{+}\right)$at $20 \mathrm{mV} / \mathrm{s}$, held for five min and subsequently brought back to $2 \mathrm{~V}$.

Ex situ Raman spectra were recorded using a Coherent Inc. Model Innova 70 argon-ion laser, $\lambda=514.5 \mathrm{~nm}$, an HR320 Spectrograph (Instruments SA, Inc.), and a EG\&G Multichannel Analyzer Model 1463. Ex situ AFM images were obtained with a Molecular Imaging (MI) scanning probe microscope coupled with a Park Scientific Instruments (PSI) electronic controller. AFM imaging was conducted in a small glove box specially designed for scanning-probe microscopy tests under a controlled $\mathrm{N}_{2}$ atmosphere. A dual-stage Scanning Electron Microscope (SEM) (model ISI-DS130C) associated with an EDAX detecting unit was used to examine the surfaces of the current collectors.

The Gas Chromatography (GC) analysis of the components in the electrolyte and products of control chemical reactions of $\mathrm{PF}_{5}$ gas with the electrolyte was performed with an HP5890 Series II instrument using a cryogenic cooling system and a flame ionization detector (FID). Each sample was on-column injected at $-15^{\circ} \mathrm{C}$ to minimize sample decomposition, and the column (DB-5) was heated to $230^{\circ} \mathrm{C}$ at $10^{\circ} \mathrm{C} / \mathrm{min}$. Control experiments were performed with standard compounds for retention-time analysis and comparison. Thermogravimetric Analysis (TGA) (Perkin Elmer TGA 7) of $\mathrm{LiPF}_{6}$ (EM Sciences, reagent) was performed using an isothermal method under flowing nitrogen.

Electrochemical characterization of anodes and cathodes were carried out in stainless-steel Swagelok cells on small samples $\left(0.6 \mathrm{~cm}^{2}\right)$ taken directly from the electrodes and studied electrochemically without any additional pretreatment. Cyclic voltammetry (CV) was carried out with a VMP multipotentiostat ( BioLogic), and cell cycling was carried out with an Arbin battery cycler. Electrochemical impedance spectroscopy (EIS) was carried out with a Solartron 1286 potentiostat and a Solartron 1260 frequency response analyzer

\section{RESULTS AND DISCUSSION}

\section{ANODE}

Typical IR spectra from different anodes are shown in Fig. 1. Because the anode samples from the virgin cell (Cell 1) were exposed to vacuum, its spectrum shows essentially no peaks characteristic of the electrolyte. A broad peak at $1650 \mathrm{~cm}^{-1}$ was observed, which is characteristic of $\mathrm{C}=\mathrm{O}$ stretching of lithium alkylcarbonate, consistent 
with other literature reports. [3]. The strong peak at $838 \mathrm{~cm}^{-1}$ is a characteristic feature of the SEI as discussed later. A similar IR spectrum was obtained for Cell 7 that was cycled at $60 \%$ SOC with a $3 \%$ SOC swing at $70^{\circ} \mathrm{C}$ except that some electrolyte peaks were also observed because the sample was not evacuated. These results suggest that the SEI was formed during the formation cycles and remained even in cells that subjected to $3 \% \Delta \mathrm{SOC}$ at temperatures as high as $70^{\circ} \mathrm{C}$. No significant signals from $\mathrm{Li}_{2} \mathrm{CO}_{3}$ were observed in either IR or Raman measurements.

To understand the role that the solvent (DEC and EC) plays in the formation of the SEI, controlled electrochemical experiments were performed in $\mathrm{DEC} / \mathrm{THF}-\mathrm{LiClO}_{4}$ and $\mathrm{EC} / \mathrm{THF}-\mathrm{LiClO}_{4}$ electrolyte. No significant SEI was detected when DEC was employed. EC was found to be the key contributor to SEI formation, as shown in Fig. 2b. The peak at $838 \mathrm{~cm}^{-1}$, which was not seen in the electrolyte (Fig. 2a), was observed again and appeared to be most intense of all peaks observed. It was ascribed by Aurbach et al. to the bending mode of an organic carbonate group [4]. This SEI, however, shows a strong resemblance to propylene oxide (Fig. 2c) which also has an intense vibrational peak at $838 \mathrm{~cm}^{-1}$ arising from $\mathrm{C}-\mathrm{O}-\mathrm{C}$ stretching of the epoxide ring. It is known that EC can be synthesized using ethylene oxide and $\mathrm{CO}_{2}[6]$.

We observed a slight non-uniformity of the SEI layer for samples from different locations on the anode in tested cells. It is most likely due to spatial variations of current density. The variation of pressure and temperature inside the cell could also play a role.

A quantitative trend analysis of SEI formation on anodes, which was carried out utilizing the $838 \mathrm{~cm}^{-1}$ peak intensity, revealed only little change of the SEI layers for the calendar life cells and for the cells that were cycled at $3 \% \Delta \mathrm{SOC}$ in the $20-70^{\circ} \mathrm{C}$ temperature range. Cells that were cycled at $9 \% \Delta \mathrm{SOC}$, however, show a deteriorated SEI at $40^{\circ} \mathrm{C}$ and no SEI for Cell 9 , which was cycled $70^{\circ} \mathrm{C}$ ). 
Electrochemical characterization of the anodes was carried out using CV and EIS. Cyclic votammograms recorded with freshly assembled cells showed continuously increasing capacity and decreasing impedance with testing time. The first slow-sweep CV recorded for anode samples from the Cells no. 1, 6 and 7 are shown in Fig. 3. The initial CVs show a trend of increasing peak separation, i.e. rise of impedance, with storage temperature. After CV cycling and three constant-current cycles with a taper charge between $0.01 \mathrm{~V}$ and $1.0 \mathrm{~V}$ vs. Li, the capacity of the anode samples stabilized at $\sim 2.1$ $\mathrm{mA} / \mathrm{cm}^{2}$, as expected for this electrode. A steady-state CV trace is also shown in Fig. 3. Similar CVs were recorded for all the anode samples following this cycling protocol. The fact that this impedance decreases with cycling indicates possible formation of a resistive film or precipitates on the anode after removal of the volatile component, DEC, from the electrolyte. This layer then re-dissolves in the relatively large amount of electrolyte introduced in the Swagelok cells. The extent of formation of this resistive film appears to follow the trend of increasing with cell storage/test temperature. This film could be related to the epoxide peaks observed with FTIR as discussed above

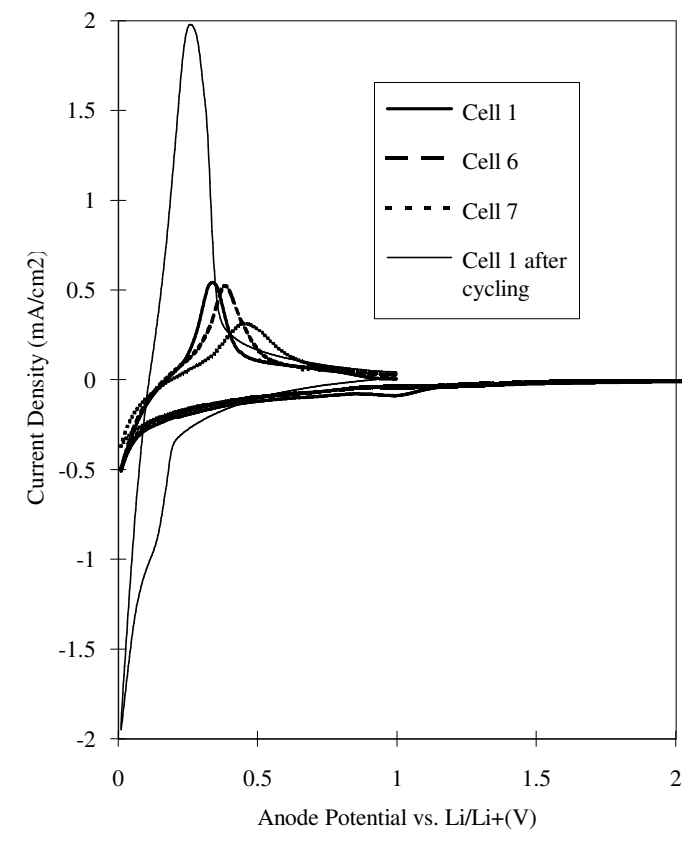

Fig. 3. Cyclic voltametry of anode samples from cells tested/stored at three temperatures. Cell 1: formed only at $25^{\circ} \mathrm{C}$; cell 6 : cycled at $40^{\circ} \mathrm{C}$; cell 7 : cycled at $70^{\circ} \mathrm{C}$.

\section{CATHODE}

Figure 4 shows topographic AFM images of the cathode extracted from Cell 1 (a), and Cell 7 (b) which was cycled at $70^{\circ} \mathrm{C}$ at $60 \%$ SOC and $3 \% \Delta$ SOC. Examination of the topographic AFM images of the cathode that was extracted from the cell that was
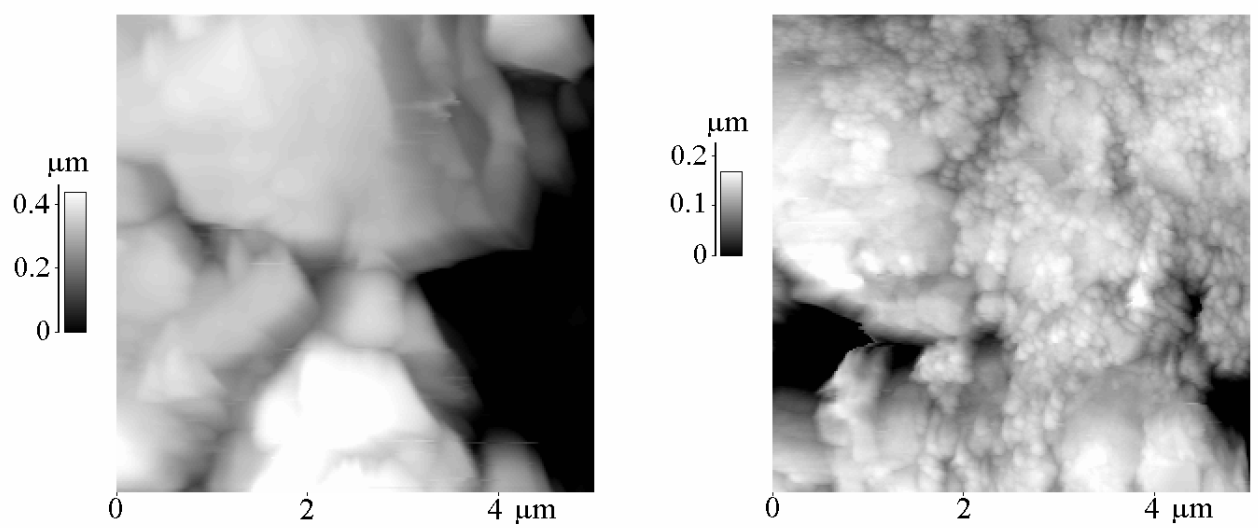

Fig. 4. AFM topographic images of cathodes from the (a) Cell 1, and (b) Cell 7 (cycled at $70{ }^{\circ} \mathrm{C}$ at $60 \%$ SOC and $3 \% \Delta$ SOC) 
cycled at $70^{\circ} \mathrm{C}$ (Fig. 4b) reveals a significant change in the surface morphology. The initial large and flat grains of active material are still recognizable, but the entire surface is now covered by nanocrystalline deposits. The individual particles sizes varied from 50 to $200 \mathrm{~nm}$. Considerable amounts of this deposit accumulated, particularly in the intergranular spaces, however the nanoparticles can also be found scattered randomly across the crystal planes of the active material.

Interestingly, we found a similar type of deposit on surfaces of almost all cathodes from cells that were subjected to either the calendar-life or life-cycle tests. In order to quantify the AFM results and identify a clear relationship between the cathode surface morphology changes and the testing temperature, a statistical analysis of the AFM images was carried out. Figure 5 shows the surface-average and rms roughness parameters expressed versus temperature. The results at $20^{\circ} \mathrm{C}$ correspond to the uncycled Cell no.1. It is clear from Fig. 5 that both surface roughness parameters decrease monotonically with increasing temperature. This trend is consistent with visual observations from the AFM images. The nanocrystalline deposit, which accumulated preferentially in deep cavities between the grains of active material, smoothed the surface to some extent. The decreasing gap between the surface-average and rms roughness values at higher temperatures

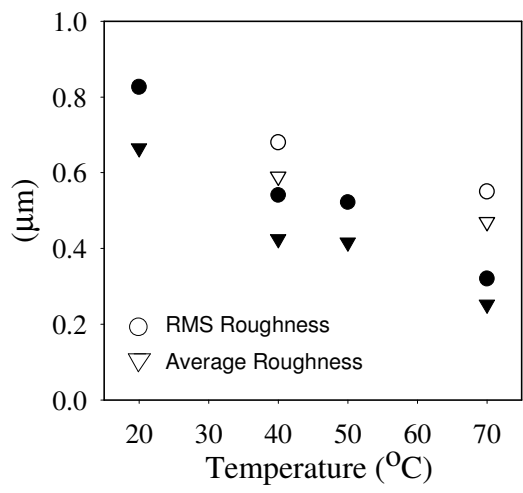

Fig. 5. Surface-average and rms roughness parameters of cathodes from the virgin cell (no. 1), calendar-life cells no. 2, 3, 5 (filled symbols) cycled cells no. 6 and 7 (open symbols) expressed versus temperature suggests the formation of a more uniform surface with less protrusions and deep crevices. Interestingly, the smoothing effect was more pronounced in the calendar-life cells compared to the cycled cells. Such behavior suggests a precipitation mechanism of deposit formation rather than an electrochemical dissolution/redeposition process.

To gain additional insight into the nature of the nanocrystalline deposit we studied the cathode surface with Raman spectroscopy. Figure 6 shows Raman spectra of cathodes from Cells 1 (a) and 3 (b). The Raman spectra of both cathodes are dominated by two strong and broad carbon bands at 1365 and $1580 \mathrm{~cm}^{-1}$ and a broad maximum centered around $500 \mathrm{~cm}^{-}$ 1, characteristic for $\mathrm{LiNi}_{\mathrm{x}} \mathrm{Co}_{1-\mathrm{x}} \mathrm{O}_{2}$ oxide. Close examination of the Raman bands that arise from $\mathrm{LiNi}_{\mathrm{x}} \mathrm{Co}_{1-\mathrm{x}} \mathrm{O}_{2}$. reveals that almost all cathodes which were tested at higher temperatures, exhibits an intense peak at $558 \mathrm{~cm}^{-1}$. This band, along with the band at $480 \mathrm{~cm}^{-1}$, is usually associated with vibrations characteristic of $\mathrm{Ni}(\mathrm{III})$ and/or Ni(IV) oxides, and their presence can be detected in the spectrum of fresh cathodes. However, the rise of their intensities suggests selective dissolution of cobalt from the $\mathrm{LiNi}_{\mathrm{x}} \mathrm{Co}_{1-\mathrm{x}} \mathrm{O}_{2}$ or the formation of a separate phase 
of nickel oxide at the cathode surface. The presence of a nanocrystalline deposit at the cathode surface supports this hypothesis. Mid-IR (wave number range $600-4000 \mathrm{~cm}^{-1}$ ) data revealed no observable SEI layer on the cathode surface, which suggests the precipitate does not arise from oxidation of the electrolyte. We may assume that in the long term such phase changes combined with extensive electrode surface morphology modifications can lead to significant electrode degradation and eventual failure.

The electrochemical performance of the cathodes showed no discernable loss in bulk capacity as a function of test temperature or cycling history. However, slow-sweep voltammetry showed that lower current for the higher-temperature cells reflects higher cathode impedance. This trend in the impedance of the cathode samples was characterized more completely with EIS. A single low-frequency $(100 \mathrm{mHz})$ specific impedance is shown in Fig. 7 as a function of electrode SOC, as characterized by the electrode potential vs. lithium. There is a clear rise in cathode impedance at low SOC or high lithium content, consistent with literature results for these oxides. There is also a clear rise in impedance over the entire range of lithium content as a function of cell tested temperature. This could be directly related to the reduction in active material surface area in the cathode as observed with AFM results discussed above or the corrosion of the current collectors as discussed below.

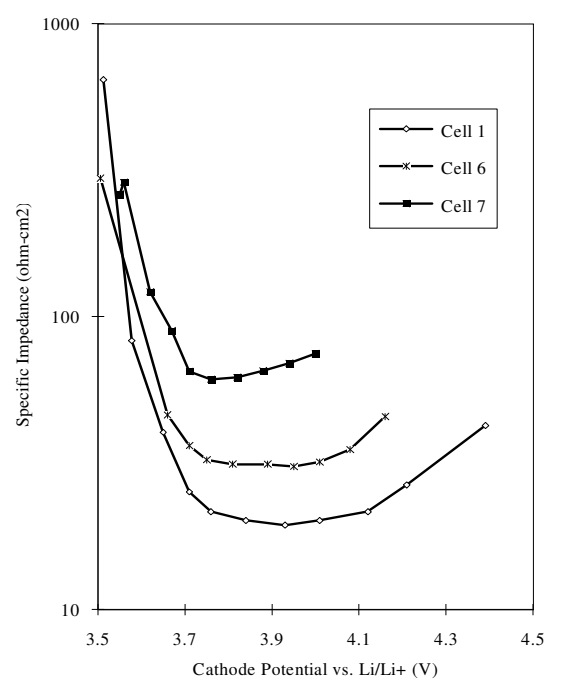

Fig. 7. Specific Impedance measurements at low frequency $(100 \mathrm{mHz})$ cathode samples from cells tested/stored at three temperatures. Cell 1 : formed only at $25^{\circ} \mathrm{C}$; cell 6 : cycled at $40^{\circ} \mathrm{C}$; cell 7: cycled at $70^{\circ} \mathrm{C}$

\section{CURRENT COLLECTORS}

Surfaces of current collectors from both the anode and cathode were examined via SEM. The $\mathrm{Cu}$ anode current collector surface showed no visible damage due to cell testing. Aluminum cathode current collectors, however, showed extensive pitting corrosion. Figure 8 presents three typical SEM images of $\mathrm{Al}$ current collectors obtained from calendarlife cells tested at 20,50 and $70^{\circ} \mathrm{C}$ (Cells no. 1,3 and 5). The pit number density is clearly correlated to testing temperature. Figure 9 shows that the pitting density doubled at elevated temperature, and that there is a clear break in behavior at $50^{\circ} \mathrm{C}$.

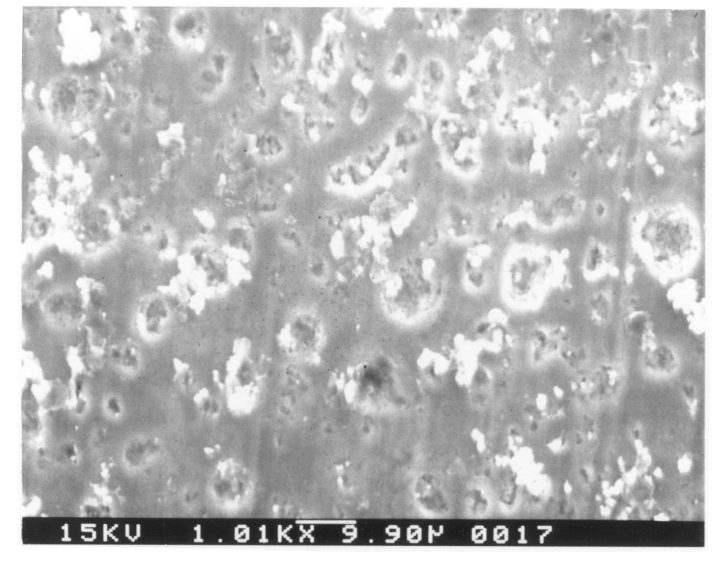

Fig. 8. SEM of the $\mathrm{Al}$ current collector from the cell stored at $70{ }^{\circ} \mathrm{C}$.

It has been proposed that the highly oxidizing potential at the cathode is the primary factor that causes the surface corrosion of $\mathrm{Al}$ current collectors [6]. Our data show that pitting corrosion is present in both the calendar-life cell, and the virgin cell. A 
pit number density as high as $4.2 \times 10^{3} /$ $\mathrm{mm}^{2}$ was observed, with a $5 \%$ variation from sample to sample. The pit dimensions of $\sim 10 \mu \mathrm{m}$ are similar to the particle size of the cathode materials used. In addition, only $\mathrm{Al}, \mathrm{Fe}$ (a trace amount), $\mathrm{Ni}$ and $\mathrm{Co}$ (cathode constituents) were detected inside the corrosion pits. The corrosion phenomenon may be initiated by the surface damage when electrode material was laminated to the Al current collectors.

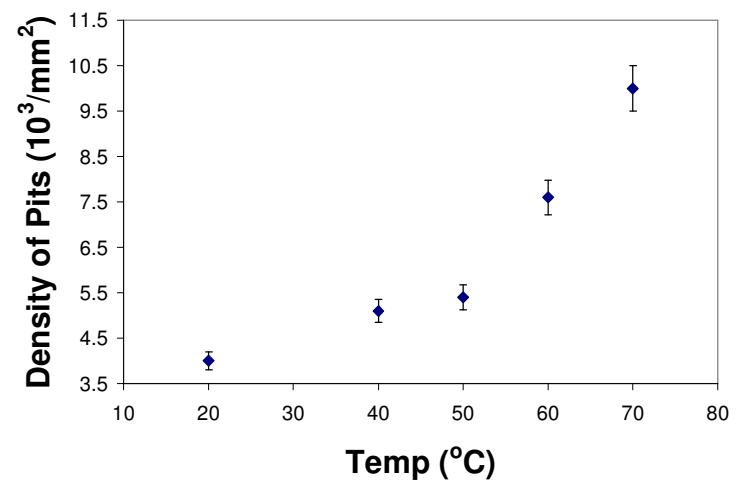

Fig. 9. The correlation of pit number density on $\mathrm{Al}$ current collectors and cell temperature.

\section{ELECTROLYTE}

Electrolyte samples were removed from the cathode, anode and separator. A GC trace (Fig. 10) from material extracted from the separator sample of cell 3 shows EC/DEC solvents as well as reaction products. These compounds and solvents were also

\begin{tabular}{|c|c|c|c|}
\hline \multirow{7}{*}{ 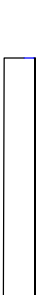 } & Pk\# Ret Time (Min) & Area \% & Identification \\
\hline & 15.85 & 2.8048 & Reaction Product \\
\hline & 6.15 & 11.3624 & Reaction Product \\
\hline & $\begin{array}{ll}3 & 8.61 \\
\end{array}$ & 3.6082 & $\mathrm{DEC}$ \\
\hline & $4 \quad 11.68$ & 72.1361 & $\mathrm{EC}$ \\
\hline & $\begin{array}{ll}5 & 16.64 \\
\end{array}$ & 9.5739 & RP 5 \\
\hline & $\begin{array}{ll}6 & 22.77 \\
\end{array}$ & 0.5146 & Reaction Product \\
\hline
\end{tabular}

observed in the anode and cathode, but only the anode contained ethylene glycol, which could be a product of the reaction of epoxide with water moisture in the air. This finding is consistent with the IR observation on the anode surface.

The reaction product at retention time $16.7 \mathrm{~min}$ (RP5) is probably an oligomer due to its long retention time. Comparing the peak area in the GC trace for the reaction product RP5 and that of EC provides quantitative information about the products created during cell testing. EC was chosen as an internal standard due to its much lower volatility at room temperature. All of the cells tested in this study (except the virgin cell) exhibited nearly the same 0.13 ratio of RP5 : EC, except that significantly less RP5 was detected in the virgin cell.

$\mathrm{LiPF}_{6}$ salt is not stable at elevated temperature. The isothermal TGA shows that a sample of $\mathrm{LiPF}_{6}$ loses $80 \%$ of its mass (likely to be $\mathrm{PF}_{5}$ ) after $200 \mathrm{~min}$ at $70^{\circ} \mathrm{C}$ under flowing nitrogen, then reaches a final value of $17 \%$ after heating to $150^{\circ} \mathrm{C}$, indicating residual $\mathrm{LiF}$. The reactive gas sublimes from solid $\mathrm{LiPF}_{6}$ salt in an equilibrium reaction 
that is sensitive to temperature. Decomposition can be described by the equilibrium equation

$$
\mathrm{LiPF}_{6}(\mathrm{~s}) \rightarrow \mathrm{PF} 5(\mathrm{~g})+\mathrm{LiF}(\mathrm{s})
$$

To understand the reaction mechanism in these Li-ion cells which contain $\mathrm{LiPF}_{6}$, a comparison between reactions of electrolyte components and $\mathrm{PF}_{5}$ gas was carried out. The reactivity of $\mathrm{PF}_{5}$ gas and electrolyte components was apparent at room temperature: a mixture of $\mathrm{PF}_{5}$ and $\mathrm{DEC}$ produced a white precipitate and gas, but the solution remained clear. When $20 \mathrm{~mL}$ of LP40 electrolyte was exposed to $0.1 \mathrm{~g}$ of gas, after $10 \mathrm{~h}$ the electrolyte turned brown, produced gas, and precipitated solid, a reaction which continued for three weeks (in a dry box) before stabilizing. We conclude that reactions involving $\mathrm{EC}$ are responsible for the insoluble brown product, furthermore, these reactions are likely responsible for the visible brown stain observed on each cell separator. The LP40 control reaction produced soluble components observable with GC, similar to those for the cell seen in Fig. 14, and the ratio of product $\mathrm{RP}_{5}$ to EC is similar to that in cells $(\mathrm{RP5}: \mathrm{EC}=0.15)$. Therefore, the reactions of $\mathrm{LP} 40$ and $\mathrm{PF}_{5}$ are expected to be responsible for the formation of RP5 both in the control reactions and in the ATD lithium ion cells.

\section{CONCLUSIONS}

An SEI is formed on the anode surface during cell formation cycles, and no changes were detected by IR for a cell that was cycled at $3 \% \Delta \mathrm{SOC}$ and $70^{\circ} \mathrm{C}$. Iinfrared spectra of this surface layer showed a strong resemblance to that of propylene oxide. Non-uniformity of the SEI layer was, however, observed for samples from different locations on the anode in tested cells, which is likely due to spatial variations of current density. The impedance of cathode samples increased monotonically with temperature. A significant change in morphology of the cathode surface with temperature was observed with AFM for the calendar life and cycled cells. The nanocrystalline deposit, which accumulated preferentially in deep cavities between the grains of active material, was identified to consist of separate nickel (III, IV) oxide phases. Severe pitting corrosion in the Al current collector was observed with SEM. Ethylene glycol was identified in the electrolyte as a reaction product from the anode. $\mathrm{LiPF}_{6}$ salt was found to be unstable at elevated temperature and could also contribute to the cell performance decline.

\section{ACKNOWLEDGMENT}

This research was funded by the Assistant Secretary for Energy Efficiency and Renewable Energy, Office of Advanced Automotive Technologies, U. S. Department of Energy, under contract number DE- AC03-76SF00098. The authors gratefully acknowledge the tested cells, help and advice provided by the ATD Program participants.

\section{REFERENCES}

1. ATD test plan for ATD 18650 GEN 1 lithium ion cells, Revision 4, December 8, 1999, INEEL 
2. X. Zhang, P. N. Ross, Jr., R. Kostecki, F. Kong, S. Sloop, J. B. Kerr, K. Striebel, E. J. Cairns, F. McLarnon, J. Electrochem. Soc., submitted

3. D. Aurbach, Y. Ein-Eli, O. Chusid, Y. Carmeli, M. Babai, H. Yamin, J.Electrochem. Soc., 141, 603 (1994)

4. D. Aurbach, M.L. Daroux, P. Faguy, and E. B. Yeager, J. Electrochem. Soc., 134, 1611 (1987),

D. Aurbach, Y. Ein-Ely, and A. Zaban, J. Electrochem. Soc., 141, L1 (1994)

5. L. Vogdanis, W. Heitz, Makromol. Chem., Rapid Commun., 7, 543 (1986)

6. J. W. Braithwaite, A. Gonzales, G. Nagasubramanian, S. J. Lucero, D. E. Peebles, J. A. Ohihausen and W. R. Cieslak, J. Electrochem. Soc., 146, 448 (1999); Y. Chen, T. M. Devine, J. W. Evans, O. R. Monteiro, and I. G. Brown, J. Electrochem. Soc., 146, 1310 (1999). 